\title{
A New Method in Teaching Financial Management to Students
}

\author{
Ting-Sheng Weng
}

\begin{abstract}
Financial management is one of the necessary skills in life; as one matures, the use of financial management frequency will be greatly increased. Because financial thinking can be cultivated, growing the habit of financial management and understanding financial-related knowledge at a young age can have a great effect on fostering future financial behavior. Therefore, in this study the research team integrated financial behavior education into homework assignments and encouraged students to improve. The research team asked students to take the costs of a specific period of school time as the subject of study and then use software to make an animation of their financial management while acquiring software application skills. For example, Student A, through the homework preparation process, paid attention to the impact of financial behavior. From the animation of charts and figures, it was apparent that Student $A$ had acquired mathematical quality, scientific quality, aesthetic quality, and management quality. Student A eventually became a maker by creating an animation about financial management and cultivating a problem-solving spirit. In this progress, Student A's STEAM (science, technology, engineering, art, and mathematics) abilities were upgraded, as were Student A's innovative, independent thinking and problem-solving skills.
\end{abstract}

Index Terms-Financial thinking, self-breakthrough, financial behavior education, financial management animation.

\section{INTRODUCTION}

\section{A. Research Background}

Financial management is a lifelong matter and an integral skill for development in modern life. Therefore, the importance of financial thinking should not be lower than that of one's career, because for the job, eventually there will be a time to retire, but financial management will continue to affect people's lives [1].

Financial management is a habit, and it can be developed from a young age. Once upright values and financial thinking are cultivated, individuals can reap great benefits from them. Financial management has become more and more important as time goes by; therefore, children should be involved in financial activities during their student years to implement financial education [2]-[5].

College students' financial education mainly focuses on teaching students financial thinking, cultivating financial skills, improving students' financial quotient, and guiding students to set up the correct financial outlook, as well as outlooks on life and values [6]. Therefore, this study designed a new method of financial education by recalling and practicing a work design from scratch, thereby encouraging students to break through themselves. The research team asked students to take the total costs incurred during a period of study as the subject of learning. By using science and technology software to help make a description and analysis of the role of their financial situation, students would be able to grasp the importance of thinking about financial management, and then make endeavors toward the practical application of financial knowledge.

\section{B. Research Motives and Purposes}

Business majors need to develop corresponding skills in order to face the ever-changing employment environment; therefore, these students should study and practice the knowledge of various theoretical and practical business skills, which will have a practical effect on their future careers and life management. In the curriculum, titled Management and Life, the research team mentioned to the students that money and living expenses are related, and that they are also closely related to mathematics. Therefore, at the self-discipline and self-management learning level, it is necessary to pay attention to the training of financial thinking and abilities and learn to use financial management thinking to face practical problems in life, so that its value can be realized and people's lives enriched.

Self-review of past memories is important; through retrospect, one can break through the old self and perform out-of-the-box thinking. Therefore, the research team encouraged students to review their high school spending, so as to educate them about the importance of financial management.

Individuals often face a number of learning difficulties, including those pertaining to life issues, learning subjects, problem solving abilities, and creativity, etc. The improvement of these dilemmas will enhance students' learning and creative performance, which can be applied to all aspects of life and career performance. The research team hoped to guide students through the management of animation work to become makers in the spirit of doing it themselves. Through problem solving, students' STEAM abilities would be improved, as well as their innovation, independent thinking, and problem-solving abilities. The research team planned to guide students to effectively use information technology to help achieve effective and innovative work and, by reviewing high school costs, help students to seriously consider the importance of financial management, which was the main objective of this study. 


\section{A. Financial Thinking}

Financial thinking includes the following five points: 1) financial concepts and related knowledge; 2) financial quality and communication skills; 3) personal financial management characteristics; 4) financial decision-making skills; and 5) confidence in future financial planning [7]. A study found that financial guidance from parents directly or indirectly affects high school students' financial thinking, and change the students' financial attitude and financial behavior [8].

The so-called "financial management" thinking refers to the planning of the wealth of people's lives, including assets, liabilities, and income and expenditures. Due to uncertainty about the future, financial management needs to be proficient in managing risks, including personal risk, property risk, and market risk, to achieve the ultimate goal of financial balance and financial soundness [2], [9]. In different times, financial thinking has also varied [10]. As financial markets become more and more complex, numerous and varied financial products continue to appear on the market, therefore the enhancement of financial thinking has become a top priority. No matter the economic situation is well-off or strained, individuals must develop proper financial thinking, and personal finances should be managed with prudence. Because finance is an unavoidable topic for everyone; the sooner individuals establish correct financial management ideas, the earlier these ideas will have a beneficial influence to individuals' financial thinking [11].

\section{B. Emphasis on Financial Behavior Education}

In the United States, financial behavior education is a special application of economic education and is inseparable from daily life. Financial behavior education teaches students about money management, personal finance, credit reports, credit cards, and other related knowledge and application abilities [11], [12].

Financial education in their study, and their definition was in agreement with that of the Ministry of Education Syllabus and Financial Literacy \& Education Association [13], however they added three viewpoints to the relevant financial education courses: the concept of money, earning more and spending wisely, and saving plans. Then, according to student level and understanding, they designed suitable materials for the introduction of different learning areas of the subject-type curriculum content.

In Taiwan, the Ministry of Education has not previously published educational materials for financial education that are applicable to all grades, and a complete curriculum for financial education in the high school curriculum is lacking. Therefore, this study used the 2009 issue of Personal Finance in High School by Financial Supervisory Commission, R.O.C, as well as the Financial Literacy and Education Association's course syllabus as the core curriculum for financial education in high school [11].

Through proper curriculum design, the integration of financial behavior education into the curriculum will be of great benefit to students' future financial behavior and thinking [14]. Therefore, the management of financial behavior knowledge, personal finance and other related knowledge into management and life in the classroom will have a profound impact on the education of students.

\section{Financial Animation}

In recent years, with the development of information media technology, human life patterns have produced drastic changes. With the popularity of web media and a wide variety of applications, individuals are in a diverse technology media environment that includes animations, videos, video games, and movies, and there are more intense sensory stimuli than ever before [15].

With the changing trends, digital images have become the mainstream of the market, and animation is no longer an entertainment and subculture. Because of people's interest in popular animation, it has long penetrated and affected social life, and it has become a part of contemporary culture and art [15]-[17].

Currently, animation is popular among the young generation, and the financial industry is using animation. FSTIC, Capital Investment Trust, Fuh Hwa Securities Investment Trust and other market players are using animation to market financial products. Their aim is to combine traditional image advertising with gold coins and wealth with novelty, fun and unconventional topics for marketing [18]. This wave of financial management animation marketing has successfully caught the public eye and triggered the industry's high attention.

The research team made use of popular animation application methods in the classroom and discussed financial management cases from financial management and E-commerce websites with the students, in order to absorb their attention and cause strong concern, which improved the effectiveness of the financial education.

\section{Self-breakthrough: The Breakthrough Experience}

People have to understand the proper way to treat themselves and believe that it is important not to give up; such perseverance can eventually be translated into a breakthrough [19].

In the age of the network society, the realization of a virtual existence not only highlights the great expansion of the human brain's thinking function, but also constructs new meanings for the living activities of modern people. From a historical point of view of human existence, the cultural life of a virtual existence has penetrated into people's concepts and started the consciousness of human life [20]. For example, cosplay originated from animation game shows, in which people dress up and put on makeup to resemble the characters in the game. With their imaginative features, cosplay has been strongly received by young people, and it has become a platform from which the younger community can show their creativity and exhibit their imagination. Animation in the virtual characters and content, such as the reality of social phenomena and the integration of facts, can guide individuals' thinking, and it can be transformed into self-breakthrough about financial concepts.

\section{AnimAtion Production StePS}

This research used a finance-related curriculum as the experimental field, in which the students chose one stage of 
their school life as the subject of learning finance knowledge. The students were required to reflect on their school lives and make use of information software aided design, and then turn their financial management process into an animation that could demonstrate and analyze their financial management effectiveness. This study also asked the students to integrate STEAM contents into the content and utilize apps or other computer software to create animation. In addition, the students were required to hand in the general structure, reference data, and a prototype of the selected theme at an early stage. After completion of the work, the students were asked to include the motive and purpose of the topic, the production experience, and a process flow chart in a Microsoft Word file (such as Fig. 1). The minimum number of words needed to exceed 2,400.

The present study was conducted in a case-specific manner, and the subject of the case was called Student A. Student A used his high school financial experience as an example, and he set his case title as Financial Animation Production on Senior High School Students' Living Income and Expenditures. This topic, in addition to combining the STEAM methodology, also included cost items, graphs, corresponding formulas, and descriptions. Fig. 1 shows Student A's flow chart of the animation production process.

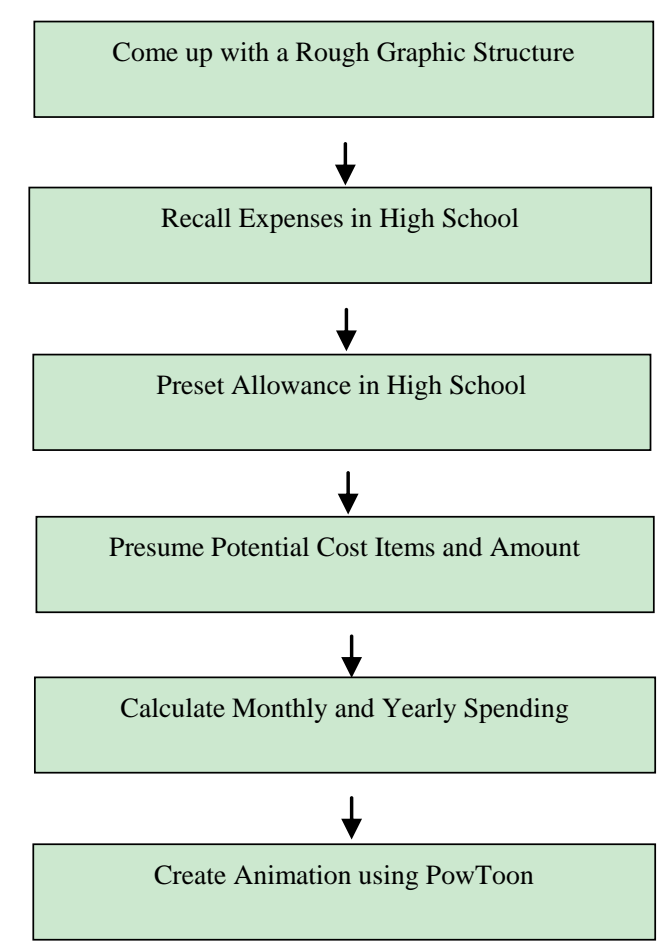

Fig. 1. Student A's process flow chart of bookkeeping animation production.

Student A's monthly expenditure chart, annual expenditure chart, descriptions, items, and so on, used the layout of the KeepAccounts: Spending Tracker app as a reference. Fig. 2 shows Student A's actual accounting status in November 2016, which was also the initial production of the animation. Because of the fact that Student A had begun bookkeeping by the end of October, he had not formed any habits, and he often missed or mistakenly recorded some items. However, as time went by, student A became more and more familiar with the bookkeeping procedures.

For Student A, in order to present simple and easy-to-understand formulas and charts in the animation, living expenses were divided into breakfast and dinner, snacks, beverages, and extra costs, and numbers were rounded off to integers. The actual number of weekdays was required to calculate the monthly expenditure needs; however, the number of days per month is not the same, therefore Student A preset one month as 30 days and then deducted four weekends to result in 22 weekdays. This number was then used to calculate the monthly expenditures. In addition, in order to present a significant financial impact, Student A deliberately set the amount of pocket money at NTD 5,000, so that the numbers from before bookkeeping and after would have some obvious differences.
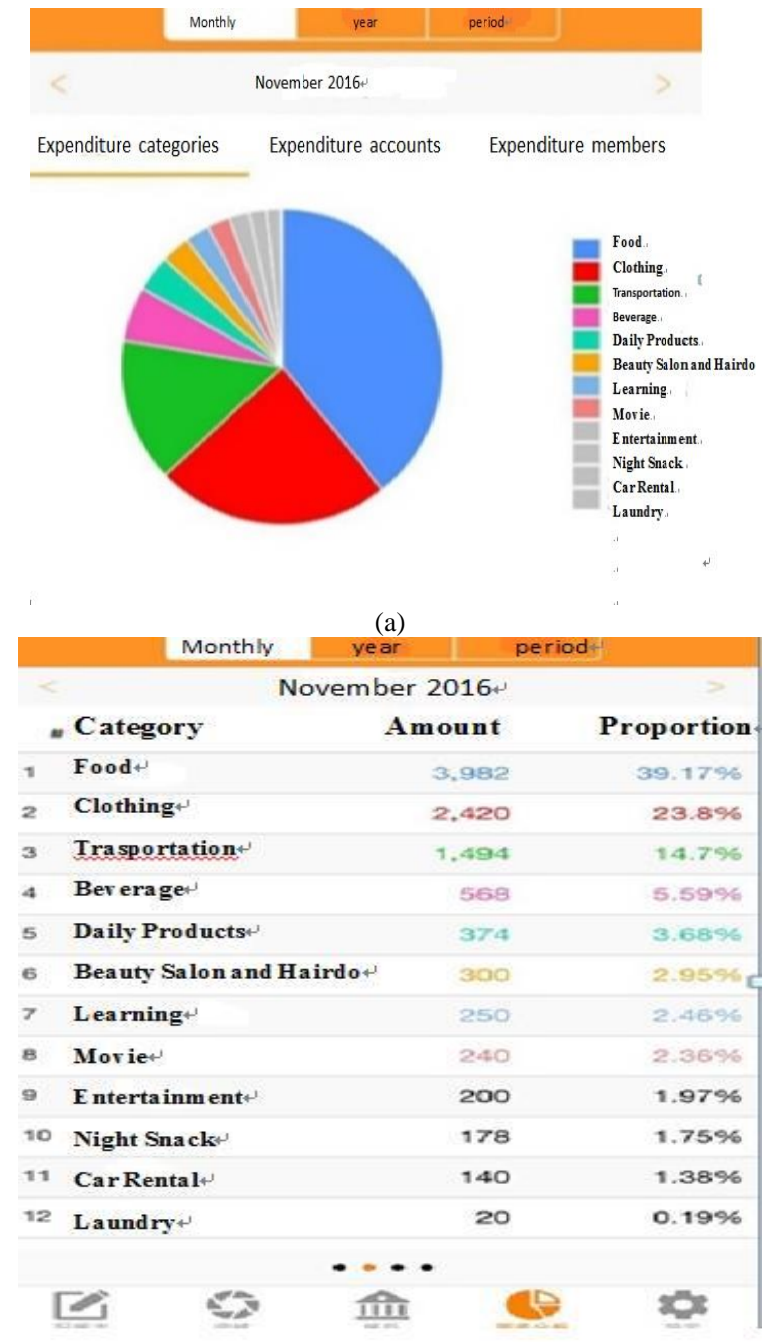

(b)

Fig. 2. Student A's use of keep accounts: Spending tracker to record actual expenses (a) and (b).

The following are some key points for Student A's participation in the study: 1) motivation for selecting this topic; 2) purpose of selecting the topic \& desired benefits; 3) using the software, reference data, and process flow chart; 4) difficulties encountered and breakthroughs; 5) value \& contribution; and 6) experience and feelings.

\section{A. Motivation for Selecting This Topic Was As Follows}

Student A did not have the habit of bookkeeping, and he later found that his expenses were large and it was not clear how his money flowed. Therefore, he took up the habit of recording his spending every day. This not only helped 
Student A to clearly know the amount of money he spent, but also to form a list of the monthly cost of items (such as Fig.2). With these records and charts, he could quickly identify where money was spent and which spending was unnecessary, and then reduce relevant spending through financial management. Student A synthesized his personal experience, which was why he chose this money-related question.

\section{B. Purpose of Selecting the Topic and Desired Benefits Were As Follows}

Student A believed that learning financial management should include the following five parts:

1) Building the right monetary values.

2) Cultivating a rational consumption attitude.

3) Cultivating the habit of saving.

4) Building the capability to manage money.

5) Developing financial planning skills.

In this animation, Student A first provided some descriptions on his day-to-day expenditures and income. Then, he showed the difference between the situations before and after financial management through a simple calculation. Compared with a traditional textual introduction, animation is more vivid and interesting, and it allows individuals to see the specific figures. Student A thought that this could allow people to more clearly understand the importance of financial management, and he hoped that viewers would pay more attention to financial management after watching the animation.

\section{Use of Software and Reference Data Were As Follows}

Student A used the KeepAccounts: Spending Tracker app from the App Store as an animation reference data, and used the PowToon website to create the High School Students Living Expenses and Self Financial Literacy animation.

Because of its simple to use features and rich built-in functions, KeepAccounts: Spending Tracker has been favored by a vast number of users. The app is an iOS system app that was released in 2015. It is divided into a free version and a paid version. The free version and paid version have the same functions; however, the paid version does not have any ads. This application has a concise look and intuitive layout to facilitate the user's actions. Not only can it preform bookkeeping and produce simple charts, it can use a password to protect the accounting data, and even set a budget to avoid excess expenditures.

PowToon is a free website that provides users with material to create animated presentations. Users need a membership to use its functions. The site is clean and tidy, which lets the users grasp the main content at a glance. The website has a variety of backgrounds, characters, pictures, and animations, which allow users to easily create a professional and dynamic briefing. However, because the PowToon website only in English, it is difficult for students who are not familiar with English to use, and they must spend more time creating projects. PowToon also has a paid version with more functions and materials, however the free version has adequate material and functions to produce exquisite works, therefore this research team suggested that students use the free version to avoid creating an additional financial burden.

In phase 1 Student A drew up the following flowchart, which is translated into English below (Fig. 3):

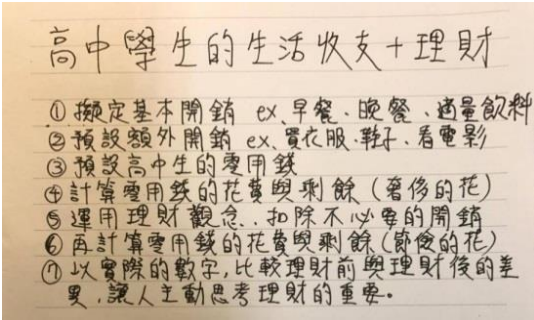

High school students' living income and expenditures + financial management

1) Come up with basic costs e.g. breakfast, dinner, moderate amount of beverages.

2) Preset extra costs e.g. buying clothes, shoes, watching movies.

3) Preset pocket money for high school

4) Calculate the surplus pocket money (assuming spending in an extravagant manner)

5) Use financial concepts to deduct unnecessary expenses

6) Calculate the surplus pocket money (assuming spending in a frugal manner)

7) Compare the difference of the actual figures before and after financial management. Raise attention on the importance of financial management.

Fig. 3. Process flow chart manuscript.

Student A's initial step process was as follows:

1) Recall the basic expenses e.g. breakfast, dinner, and a moderate amount of beverages.

2) Recall the extra cost e.g. buying clothes, shoes, and watching movies.

3) Recall the high school students' pocket money.

4) Calculate the surplus pocket money (assuming spending in an extravagant manner).

5) Use financial concepts to deduct unnecessary expenses.

6) Calculate the surplus pocket money (assuming spending in a frugal manner).

7) Compare the difference of the actual figures before and after financial management, and then raise attention on the importance of financial management.

\section{Difficulties Encountered and Breakthroughs Were As Follows}

Student A knew that the final assignment was to create an animation, and he felt very frustrated about it. Although many students had used PowToon to produce interim assignments, he had no great interest in the interim, so he did not use PowToon and just handed in his rough works. Since he did not have access to the PowToon software, he had no foundation for its usage, and he had to start from scratch. The research team provided assistance with the PowToon operation steps for 13 weeks, with different case animation instructions to the students.

The team learned that in order to overcome this difficulty, Student A began to learn how to use PowToon. First, he went to YouTube to search for and watch relevant teaching films, and then he logged into the PowToon website to grasp how to use it, all while thinking about the animation plot structure and content. In addition, he also mentioned his anxiety about completing the word file. He worried that the number of words would not reach the requirement. However, in the end he met the specified number of words, and the narration was 
complete and thorough.

\section{E. Value and Contribution Were As Follows}

The main character in the animation was drawn from the dynamic characters built into PowToon, and for different contents there were different postures and expressions, which gave the animation a playful and vivid look. Student A hoped to be able to draw in a relaxed and interesting way to let visitors think about the importance of financial management and thrift, because financial management is a necessary subject for everyone, not just high school students.

\section{F. Experience and Feelings Were As Follows}

When taking the first glance at this course's final assignment, Student A felt both troublesome and challenged, for he had no previous experience in making animation and he had no confidence in completing his production. However, he mustered up the courage to finish it. During the process he also encountered numerous difficulties, and he was at a total loss at the beginning. He could only go online to search for recommended tools and software. He decided to use PowToon for his production because in the classroom he often saw the author playing short PowToon films. Therefore, he was more familiar with this software than other software. Because it was his first attempt to use PowToon, he spent a lot of time searching for data and teaching films. After step by step learning, he became increasingly familiar with PowToon. He also admired other students who produced excellent PowToon works with content that was rich and full of details.

From the process Student A learned how to create animation. He finally thought that the course was worth his while, and that he was fortunate to have engaged in this homework. Without this homework, he would not have tried making animation at all. Although at the beginning he felt reluctant and troubled, after completing the work he found that everything was worthwhile. He not only had a sense of achievement, but also learned skills thanks to his courage to make breakthroughs. These skills could be handy in his future workplace and throughout his entire life.

Student A's homework results are shown as Fig. 4 (a) to (o) (these pictures have been authorized by Student A).

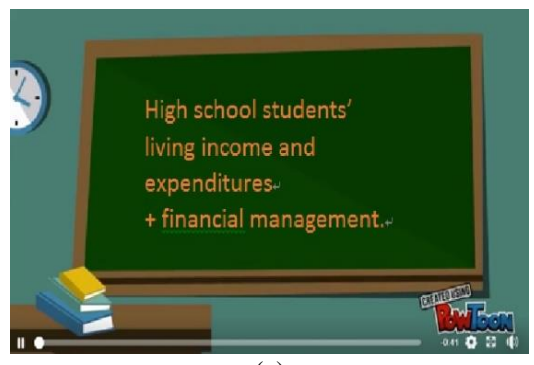

(a)

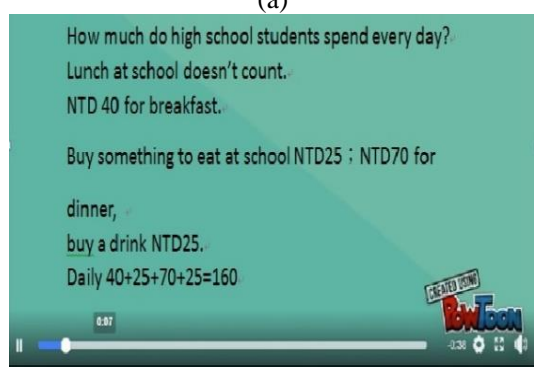

(b)

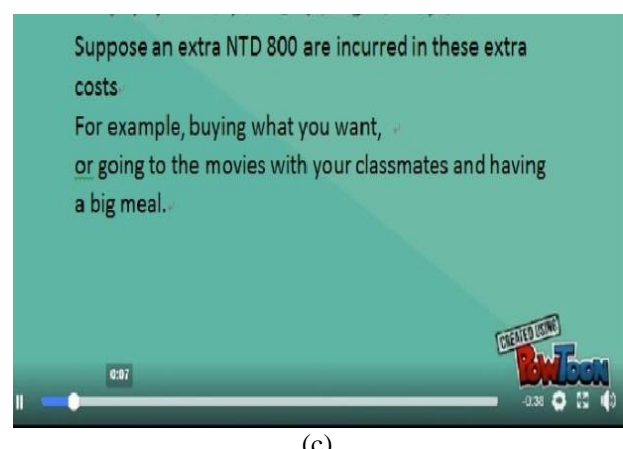

(c)

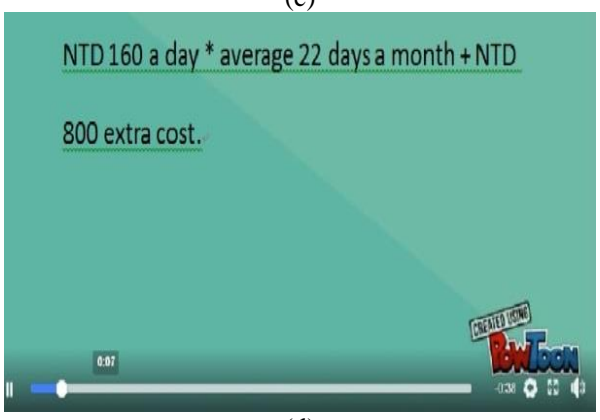

(d)

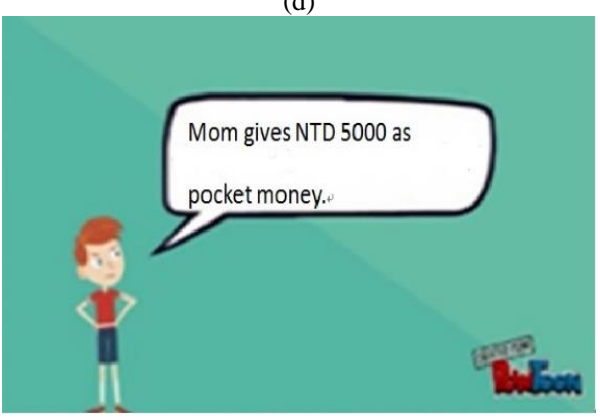

(e)

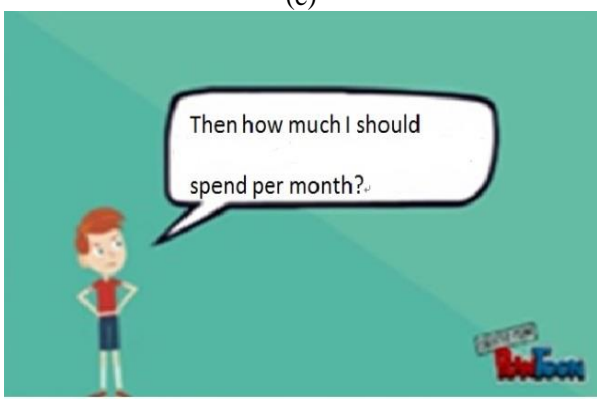

(f)

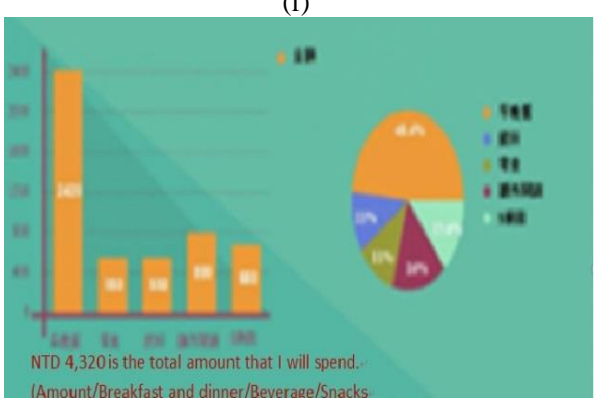

(g)

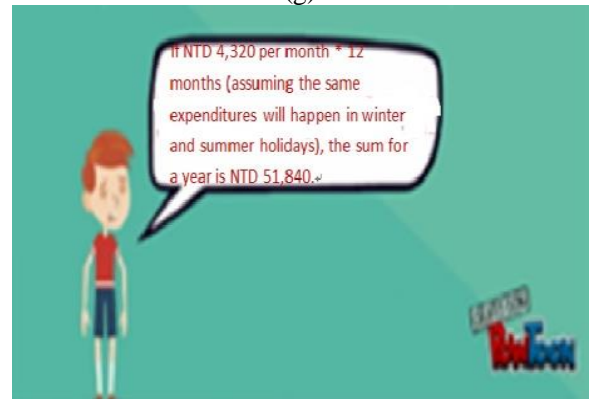

(h) 


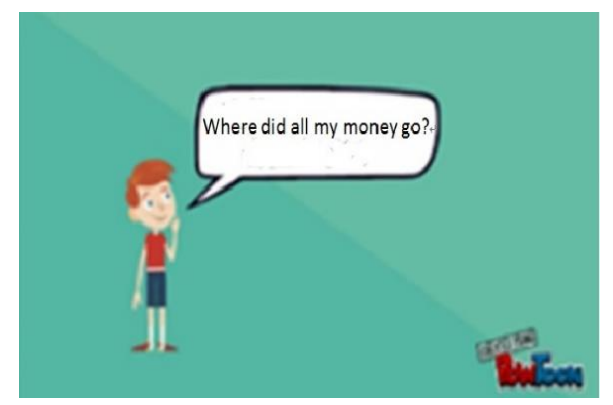

(i)

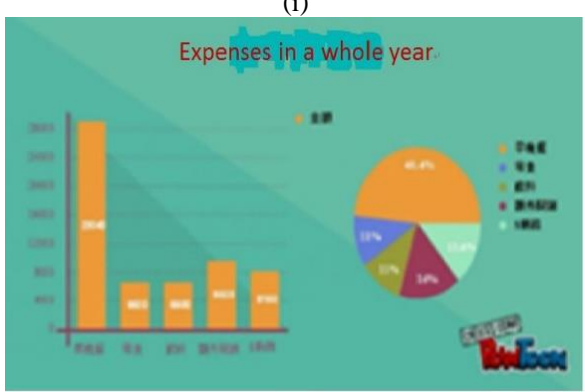

(j)

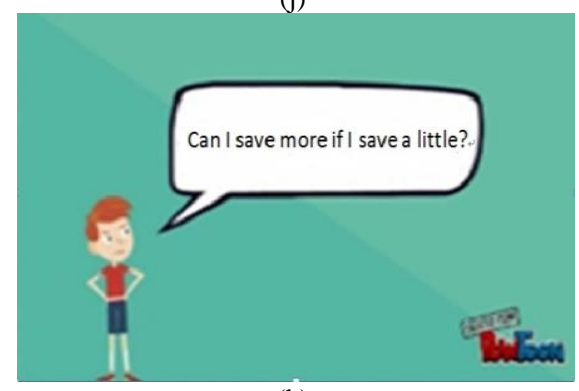

(k)

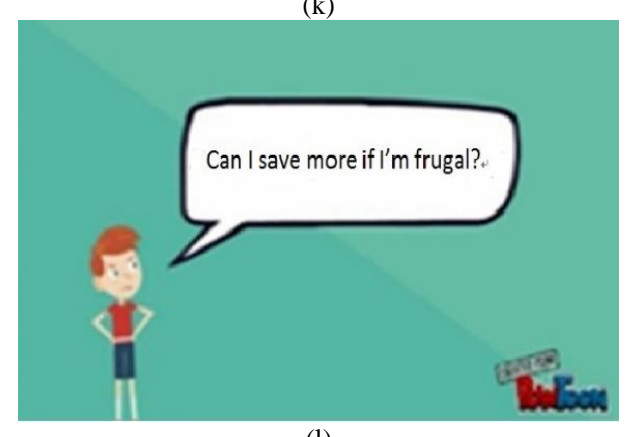

(1)

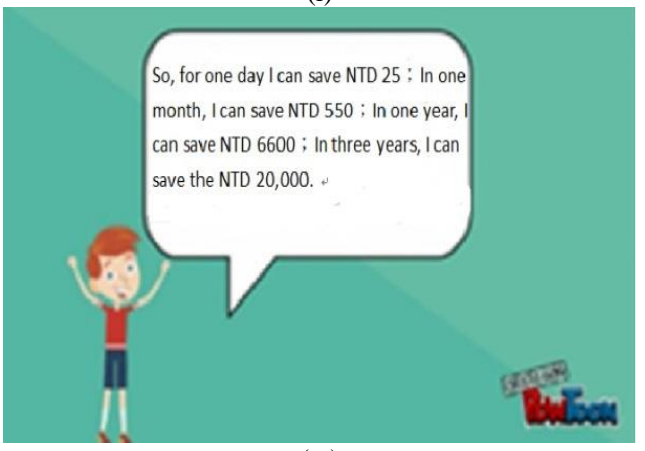

(m)

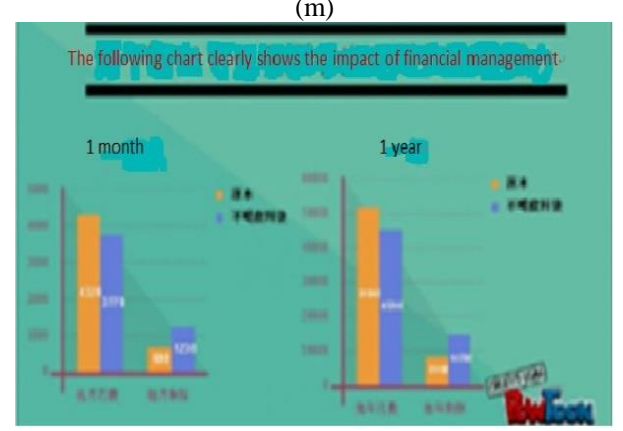

(n)

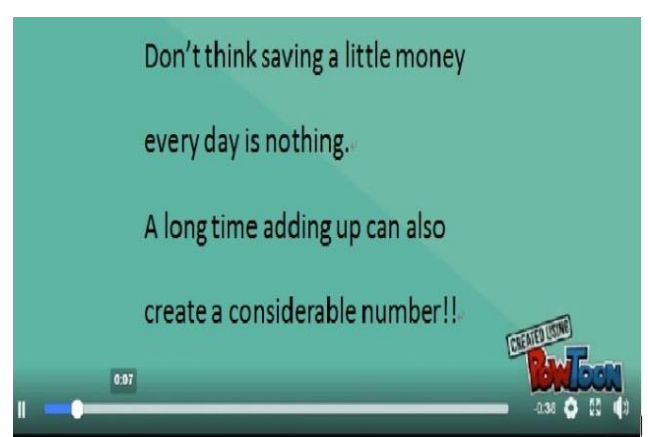

(o)

Fig. 4. Living expenses and self-financing literacy animation screen capture from picture (a) to (o).

\section{CONCLUSION}

Business students need to develop corresponding skills to face the changing employment environment. It is the duty of teachers to establish a suitable learning environment to help students acquire new knowledge. This research showed a new strategy of business management learning, and explored the feasibility of this strategy from Student A's practice. As far as Student A's learning process is concerned, he had no animation basis, did not know how to use PowToon, and was not proficient at writing ideas at first. Gradually he picked up the knowledge needed to deliver an easy-to-understand financial animation; he also managed to hand in a report that met requirements and was coherent in content. He learned from the class that an individual's efforts and self-breakthrough could result in unlimited possibilities. This also proved the necessity and importance of education.

The research team guided students in the classroom to flip their thinking, so that the students could understand the benefits of combining animation with education. The process caused a small number of students to feel dissatisfied and helpless, as they thought that taking this course would force them to deal with a big problem. However, thanks to the author's patient teaching and guidance, as well as advice on their homework, after a long production process, the students had a breakthrough. They felt that they had gained the knowledge, skills and courage to needed to break through themselves. They were no longer limited to thinking about finishing the assignment, but now wanted to gain more knowledge and work hard to create their projects. At the end of the semester the students felt the time had gone by quickly, and they wanted to learn more knowledge and skills. This motivation to learn was the first step in success.

Yearning for a comfortable study life is human nature. Therefore, unavoidably, the students had the same hope that the course content would be easy and that getting credits would not take a lot of trouble. However, as teachers, it is important to ensure that the curriculum design has educational value and can let the students obtain knowledge; through periodic individual guidance, teachers want to encourage all students to study and succeed, as well as arouse the classmates' resonance and their desire for knowledge.

This study embedded the financial behavior education project in the management and life curriculum, so that students could absorb money-related knowledge. During the production process this course also guided students to 
manage the thinking of financial management by themselves. Student A recalled high school memories and the use of integration techniques in animation technology to create an animation about high school students' living expenses and self-financial literacy, and in so doing he acquired multiplex integration technology. The presentation of graphs and figures revealed that Student A had mathematical literacy, scientific literacy, aesthetic literacy, and management literacy (management of personal finance), and this was in line with the STEAM (science, technology, engineering, art and mathematics) education policy promoted by the Ministry of Education. This study found that the students learned basic knowledge, skills and financial literacy in the course, and these represented the learning benefit of the course content.

\section{SugGestions}

This animation only divided high school students' expenditures into breakfasts, dinners, snacks, beverages, and extra expenses; however, extra expenses can be subdivided into many items, such as transportation, recreation, clothing, and so on. Since the income and expenditures of each high school student are different, this study proposed that more data from all sources should be collected and averaged in the future, so that more accurate charts and calculations can be made using the income and expenditures of most high school students and the average figures.

\section{ACKNOWLEDGEMENT}

The authors appreciate the comments of the review committee. This study was financially supported by the Ministry of Science and Technology under grant no. MOST 106-2511-S-415-013-MY2y. The authors also thank Hwang for the help in this production.

\section{REFERENCES}

[1] H. Ouyang and C. L. Wu, "Thinking and practice of financial management," 2013 International Symposium on Service Industry Globalization, pp. 1-10, 2013.

[2] Y. C. Tseng and L. H. Lee, "The effects of situated financial education on financial literacy among students in a junior high Schools in Taiwan," Middle Education, vol. 63, no. 2, pp. 111-131, 2012.

[3] K. Varcoe, A. Martin, Z. Devitto, and C. Go, "Using a financial education curriculum for teens," Financial Counseling and Planning, vol. 16, no. 1, pp. 63-71, 2005.

[4] T. M. Peng, S. Bartholomue, J. J. Fox, and G. Cravener, "The impact of personal financial education delivered in high school and college courses," Journal of Family and Economic Issues, vol. 28, no. 2, pp. 265-284, 2007.
[5] L. M. Borden, S. A. Lee, J. Serido, and D. Collins, "Changing college students' financial knowledge, attitudes, and behavior through seminar participation," Journal of Family and Economic Issues, vol. 29, no. 1, pp. 23-40, 2008.

[6] B. Liu and L. P. Xue, "Money management education in college: Significance and pathways," Journal of University Counselors, vol. 2, no. 2, pp. 7-9, 2010.

[7] Y. C. Tseng and F. L. Wang, "A path analysis of parents' financial teaching effects on children's financial literacy, attitude, and behavior of high-school students in Taichung," Commerce \& Management Quarterly, vol. 18, no. 1, pp. 51-74, 2017.

[8] D. L. Remund, "Financial literacy explicated: The case for a clearer definition in an increasingly complex economy," The Journal of Consumer Affairs, vol. 44, no. 2, pp. 276-295, 2010.

[9] Financial Supervisory Commission, "Personal finance-high School version," Taipei: Financial Supervisory Commission, 2009.

[10] C. T. Chieh, "Discussion on financial thinking in the new economic era," I ndustrial \& Science Tribune, vol. 11, no. 24, p. 104, 2012.

[11] Y. Y. Hsiao and M. Y. Huang, "A comparative study on financial curriculum between the U.S. and Taiwan," The Bulletin of Civic Education and Leadership, no. 23, pp. 103-138, 2014.

[12] A. Tate. (2007). Mandatory financial literacy courses needed in America's high Schools. [Online] Available: http://www.associatedcontent.com/article/484361/mandatory_financia 1_literacy_courses_pg $5 . h t m l$ ? cat=3

[13] L. Y. Lee, C. L. Wu, C. T. Hou, and J. S. Lo, "The effects of multimedia computer assisted instruction on the performance of financial education for elementary children with intellectual disabilities," Journal of Research in Special Education and Assistive Technology, no. 6, pp. 23-41+43, 2013

[14] M. Y. Huang, W. T. Lai, and C. M. Lu, "The effectiveness of implementation on the integration of financial education into junior high school established curricula," Bulletin of Civic and Moral Education, no. 22, pp. 39-74, 2013.

[15] Y. C. Hsieh, "Assessment criteria research about how to choose animation for art instructional materials in senior high schools," Middle School Education, vol. 65, no. 1, pp. 112-133, 2014.

[16] R. G. King, "Computer graphics and animation as agents of personal evolution in the arts. Leonardo," Electronic Art, vol. 1, pp. 43-46, 1988.

[17] P. C. Lin and W. L. Chen, "A study of concept and medium in experimental animation," Journal of National Taiwan College of Arts, no. 76 , pp. 99-112, 2005

[18] China Times, "Financial management marketing to absorb eye with an animation style," China Times, January 13, 2015.

[19] J. F. Demartini, Y. N. Chang and C. W. Chiang, The Breakthrough Experience, California: Hay House, 2002.

[20] C. C. Cheng and C. K. Yin, "A study of the meaning of virtual existence," Studies in Dialectics of Nature, no. 2, pp. 54-56, 2001.

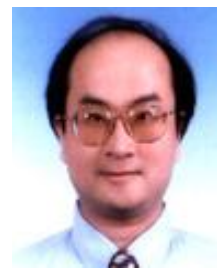

Ting Sheng Weng is an associate professor of the Department of Business Administration at National Chiayi University, Taiwan. He received his $\mathrm{Ph}$. D. in division of management and information science, Graduate School of Advanced Technology from Kinki University, Japan in 2000. He had served as visiting professor at Meiji University in Japan from 2006 through 2007. His major research interests include science technology and management, e-learning, information education, technology education, MIS, animation and cartoon, and image processing. 